Revta brasil. Bot., São Paulo, V.23, n.1, p.87-96, mar. 2000

\title{
Estrutura do pericarpo e da semente de Astronium graveolens Jacq. (Anacardiaceae) com notas taxonômicas
}

\author{
SANDRA M. CARMELLO-GUERREIRO ${ }^{1,3}$ e ADELITA A. SARTORI PAOLI ${ }^{2}$
}

(recebido em 23 de junho de 1999; aceito em 5 de dezembro de 1999)

\begin{abstract}
Pericarp and seed structure of Astronium graveolens Jacq. (Anacardiaceae) with taxonomic notes). Astronium graveolens is a treelike member of the family Anacardiaceae, spreading from Mexico to the south center of South America. The fruit is a pseudosamara with a uniseriate exocarp adherent to the endocarp. The mesocarp is parenchymatic and presents large secretory ducts associated with vascular bundle and arranged side by side, near to the endocarp. The parenchymatic endocarp is biserial, and the layer enveloping the locule is slightly radially elongated. The ovule is anatropous, unitegmic, and crassinucellate and has an evident dorsal raphe and a tanniniferous hypostase. It presents an apical-lateral insertion in the ovary and shows a placentary obturator. The testa which strongly adheres to the pericarp shows the cells of the inner epidermis with dense cytoplasm, indicative of an endotestal condition. The mature seed coat is formed from the remaining of the testa, funicle, raphe-chalaza region and hypostase, presenting two distinct regions: one is dark brown patch pachychalazal and other pale brown tegumentary. The embryo is axial investing.
\end{abstract}

RESUMO - (Estrutura do pericarpo e da semente de Astronium graveolens Jacq. (Anacardiaceae) com notas taxonômicas). Astronium graveolens é um representante arbóreo da família Anacardiaceae que se distribui desde o México até o centro-sul da América do Sul. O fruto é uma pseudo-sâmara com exocarpo unisseriado, suberificado e aderido ao mesocarpo. O mesocarpo é parenquimático, com grandes canais secretores associados aos feixes vasculares e localizados próximos ao endocarpo. O endocarpo parenquimático é bisseriado, sendo a camada que reveste o lóculo ligeiramente alongada radialmente. O óvulo é anátropo, unitegumentado, crassinucelado, com rafe dorsal evidente e hipóstase tanífera; apresenta obturador placentário e está inserido em posição apical-lateral no fruto. A testa, fortemente adnata ao pericarpo, apresenta as células da epiderme interna pequenas e de conteúdo bastante denso, indicando uma condição endotestal. O envoltório na semente madura é formado por restos da testa, funículo, região rafe-calazal e hipóstase apresentando duas regiões distintas: uma paquicalazal de coloração marrom e outra tegumentar de coloração amarelo-clara. $\mathrm{O}$ embrião ocupa posição axial e é do tipo "investing".

Key words - Anacardiaceae, Astronium graveolens, pericarp, seed, anatomy

\section{Introdução}

O gênero Astronium, estabelecido por Jacquin em 1760 e pertencente à família Anacardiaceae, é neotropical e reúne espécies arbóreas, com frutos de cálice persistente e acrescente no fruto, que resulta em aspecto estrelado, sendo esta característica que dá nome ao gênero (Santin 1991).

Apesar do gênero ter sido revisado, na região neotropical, por Barkley (1968), até recentemente,

1. Departamento de Botânica, Universidade Estadual de Campinas, Caixa Postal 6109, 13083-930 Campinas, SP, Brasil.

2. Departamento de Botânica, Instituto de Biociências, Universidade Estadual Paulista, Caixa Postal 199, 13506-900 Rio Claro, SP, Brasil.

3. Autor para correspondência: smcg@unicamp.br apresentava problemas de identificação taxonômica. O gênero foi dividido por Barkley (1968) em dois subgêneros, o Euastronium, com 10 espécies e sete variedades, e o Myracrodruon, com três espécies e uma variedade. Esta conceituação foi aceita até que Santin \& Leitão-Filho (1991), empregando os caracteres mais aceitos para a delimitação genérica em Anacardiaceae que são o tipo de fruto e de placentação, retiraram o subgênero Myracrodruon do gênero Astronium Jacq. restabelecendo o gênero Myracrodruon Fr. Allem. Segundo os autores, apesar dos dois gêneros serem muito próximos, não podem ocupar o mesmo táxon genérico devido principalmente ao tipo de fruto que apresentam: o gênero Astronium possui fruto tipo baga e o gênero Myracrodruon possui fruto tipo drupa, com endocarpo anguloso. 
A classificação do tipo de fruto de Astronium ainda gera confusões, uma vez que o fruto totalmente desenvolvido, mas não pronto para a dispersão, apresenta mesocarpo parenquimático com grandes canais secretores e endocarpo não lignificado e, quando pronto para dispersão, apresenta pericarpo seco (Santin 1989). Desse modo, as interpretações para o tipo de fruto de Astronium variam, sendo classificados como baga (Barroso et al. 1984, Santin 1989, Santin \& Leitão-Filho 1991) ou como núcula (Barroso et al. 1999).

Em vista do exposto, este trabalho teve por objetivo realizar um estudo morfo-anatômico dos frutos e sementes de Astronium graveolens em desenvolvimento, visando, principalmente, fornecer mais subsídios para a tipificação de seus frutos e esclarecimento dos problemas taxonômicos, além de um melhor conhecimento da espécie.

\section{Material e métodos}

Foram utilizados flores, frutos e sementes de Astronium graveolens em diversas fases de desenvolvimento, coletados na região de Piracicaba, SP, Brasil. Os estudos morfológicos e anatômicos foram realizados em material fresco e em material fixado em FAA 50 (Johansen 1940). Foram utilizadas seções nos diversos planos anatômicos, obtidas com auxílio de micrótomo rotativo e então montadas em preparações permanentes. As lâminas permanentes foram confeccionadas com material incluído em histo-resina (glicol metacrilato), seguindo-se a técnica descrita por Gerrits (1991). O material foi seccionado em micrótomo manual com navalha tipo $\mathrm{C}$ e as secções coradas com azul de toluidina à $0,05 \%$ em tampão acetato, pH 4,7 (O’Brien et al. 1964) e montadas em resina sintética.

\section{Resultados}

Morfologia do fruto e da semente - O fruto, completamente maduro, é uma pseudo-sâmara com cálice acrescente (figura 1) com ca. de 11,4 mm de comprimento x 2,1 mm de diâmetro.

A semente, única por fruto, é estreitamente elíptica (figura 2) e provém de óvulo anátropo (figura 3 ). O envoltório da semente é membranáceo, liso, de coloração amarelo-clara com uma mancha marromescura.

Na semente madura, a micrópila não é visível, o endosperma é ausente, o embrião tem posição axial e é do tipo "investing", com dois cotilédones carnosos, maciços e planos, com lobos bem marcados; o eixo hipocótilo-radícula é curto, invaginado entre os cotilédones e apresenta plúmula pouco desenvolvida (figuras 4 e 5).

Ovário - O ovário é súpero, uniloculado com um único óvulo (figura 6). A epiderme externa é unisseriada (figura 7) recoberta por cutícula, com células alongadas no sentido radial e com núcleo evidente. O mesofilo ovariano é constituído por parênquima e canais secretores (figura 7) associados aos feixes vasculares.

A epiderme interna do ovário sofre divisão periclinal resultando em duas camadas celulares com citoplasma denso e núcleo evidente (figura 8). Na camada que reveste o lóculo, as células são ligeiramente alongadas radialmente, revestidas por cutícula.

Estrutura do pericarpo - As secções longitudinais e transversais dos frutos jovens, em fases sucessivas do desenvolvimento, mostram as seguintes características anatômicas: a) epiderme externa com células de cúbicas a alongadas radialmente, provida de estômatos (figura 9); b) zona interepidérmica parenquimática, futuro mesocarpo, caracterizada pela presença de grandes canais secretores de distribuição ordenada, localizados próximos à epiderme interna e associados aos feixes vasculares (figura 10); c) epiderme interna bisseriada, sendo a camada mais externa constituída de células poliédricas e a mais interna, delimitando o lóculo, ligeiramente alongada radialmente (figura 11).

A diferenciação das três regiões do pericarpo, durante o desenvolvimento do fruto, é muito pequena, observando-se a suberificação das células da epiderme externa, isto é, do exocarpo (sensu stricto) no fruto maduro e sua permanência aderido ao mesocarpo (figura 12). No mesocarpo, observa-se um aumento no número e no tamanho dos canais secretores e das células parenquimáticas (figura 12). Os canais secretores distribuem-se num arranjo compacto e ordenado lado a lado, em contato com o endocarpo parenquimático bisseriado (figura 12).

Durante a fase de amadurecimento do fruto, o pericarpo perde água e as células parenquimáticas colapsadas formam uma fina camada ao redor dos grandes canais secretores (figura 13). Completado o amadurecimento, o resultado é um pericarpo com 

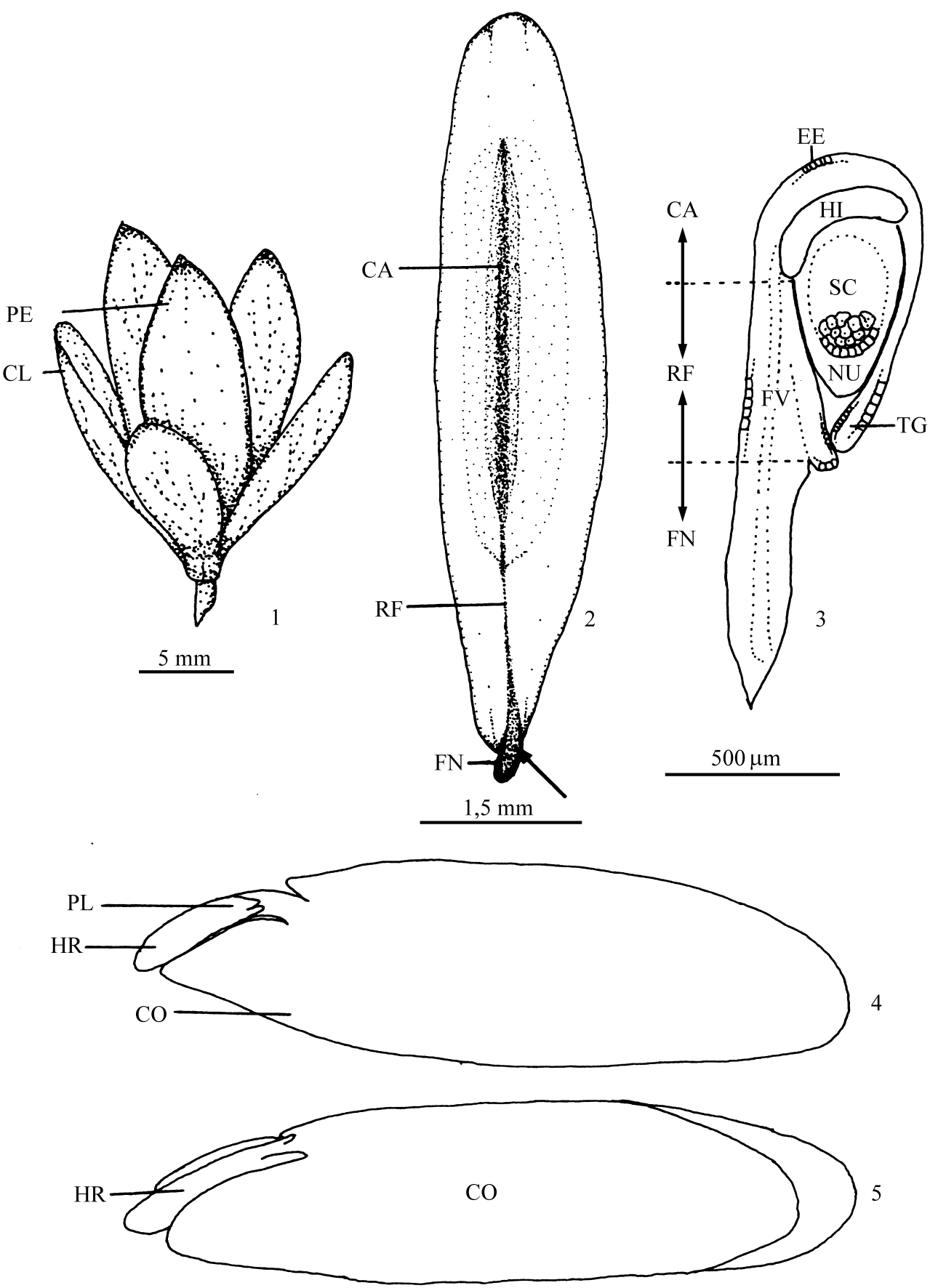

Figuras 1-5. 1. Aspecto geral do fruto maduro. 2. Aspecto geral da semente madura (seta indica vestígios de arilo). 3. Secção longitudinal do óvulo. 4. Aspecto geral do embrião com um dos cotilédones destacados, mostrando plúmula pouco desenvolvida. 5. Aspecto geral do embrião mostrando eixo hipocótilo-radícula invaginado entre os cotilédones. $\mathrm{CA}=$ calaza, $\mathrm{CL}=$ cálice persistente, $\mathrm{CO}=$ cotilédone, $\mathrm{EE}=$ epiderme externa, $\mathrm{FN}=$ funículo, $\mathrm{FV}=$ feixe vascular, $\mathrm{HI}=$ hipóstase, $\mathrm{HR}=$ eixo hipocótilo-radícula, $\mathrm{NU}=$ nucelo, $\mathrm{PE}=$ pericarpo, $\mathrm{PL}=$ plúmula, $\mathrm{RF}=\mathrm{rafe}, \mathrm{SC}=\mathrm{saco}$ embrionário, $\mathrm{TG}=$ tegumento. 


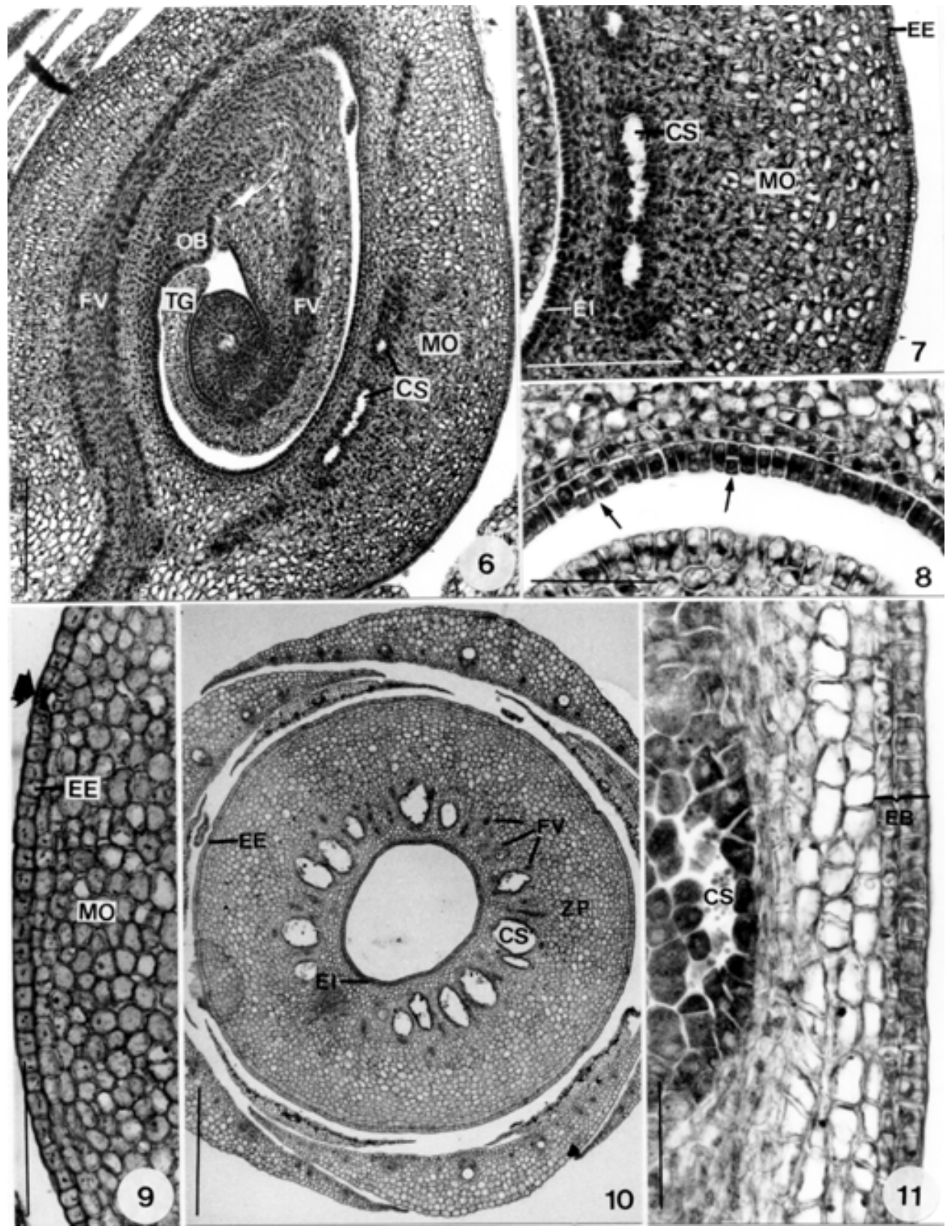

Figuras 6-11. 6. Secção longitudinal do ovário mostrando inserção apical-lateral do óvulo (barra = $150 \mu \mathrm{m}$ ). 7. Secção longitudinal mostrando a parede do ovário $($ barra $=150 \mu \mathrm{m}$ ). Figura 8. Detalhe da epiderme interna do ovário em divisão (setas) (barra $=50 \mu \mathrm{m})$. 9-11. Secções tranversais da parede do fruto imaturo. 9. Epiderme externa unisseriada. Seta indica estômato (barra $=150 \mu \mathrm{m})$. 10. Zona interepidérmica parenquimática (futuro mesocarpo) $($ barra $=500 \mu \mathrm{m}) .11$. Epiderme interna bisseriada (barra $=50 \mu \mathrm{m}$ ). $\mathrm{CS}=$ canal secretor, $\mathrm{EB}=$ epiderme bisseriada, $\mathrm{EE}=$ epiderme externa, $\mathrm{EI}=$ epiderme interna, $\mathrm{FV}=$ feixe vascular, $\mathrm{MO}=$ mesofilo ovariano, $\mathrm{OB}=$ obturador placentário, $\mathrm{TG}=$ tegumento, $\mathrm{ZP}=$ zona parenquimática. 
aspecto seco mas com os canais secretores, agora delimitados por 2-4 camadas estreitas de células, repletos de secreção. Portanto, trata-se de um pericarpo seco, porém, resinoso (figura 13).

A epiderme bisseriada dá origem ao endocarpo (sensu stricto), sem que este apresente qualquer esclerificação. No fruto totalmente desenvolvido e amadurecido, as células do endocarpo apresentamse colapsadas e fortemente adnatas à semente, sendo difícil sua delimitação (figuras 12 e 13).

Semente - O óvulo anátropo é unitegumentado, crassinucelado com rafe dorsal evidente, funículo longo e inserido em posição apical-lateral (figuras 3 e 6). Na região da micrópila, o tegumento único é constituído por seis a 12 camadas celulares (figura 14). A epiderme externa é formada por células que variam no formato de poliédrico alongado radialmente ao cúbico e são maiores que as células das camadas interepidérmicas e epiderme interna (figura 14). Na epiderme interna, as células são pequenas, cúbicas, de conteúdo denso e arranjo compacto (figura 14).

Na região da calaza, observa-se um maior número de células, sendo que um grupo de arranjo compacto apresenta compostos fenólicos e paredes espessadas, formando um capuz sobre o saco embrionário, constituindo a hipóstase (sensu lato) (figura 15). O funículo longo e a rafe são percorridos por um feixe vascular (figura 3) anficrival. Uma protuberância forma-se na placenta, em direção à micrópila, constituindo o obturador placentário (figura 6).

$\mathrm{Na}$ semente madura, o tegumento único (testa) apresenta-se fortemente adnato ao pericarpo (figura 16) e a estrutura básica do óvulo é mantida ocorrendo pouca diferenciação.

As regiões da micrópila e anti-rafe apresentam poucas camadas de células, sendo mais evidentes a epiderme externa, com células cubóides ligeiramente alongadas radialmente, e a epiderme interna, com células cubóides pequenas. As células das camadas interepidérmicas possuem formato variado e espaços intercelulares conspícuos, apresentando, em muitos locais, células colapsadas e sem qualquer especialização.

$\mathrm{Na}$ região calazal, em corte transversal, o tegumento apresenta um maior número de camadas celulares. Na epiderme externa, as células são
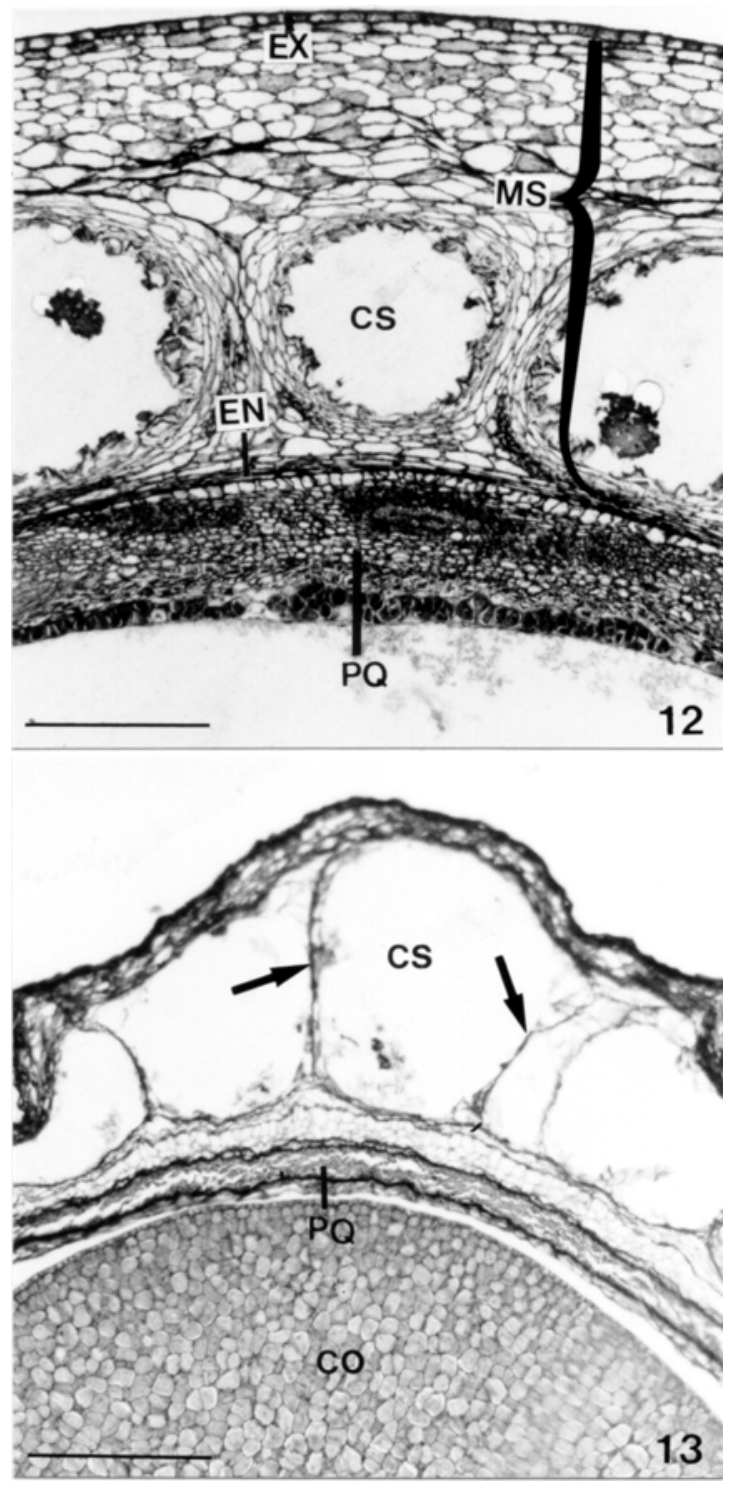

Figuras 12-13. Secções transversais do pericarpo. 12. Pericarpo totalmente desenvolvido mas não amadurecido (bar$\mathrm{ra}=250 \mu \mathrm{m}) .13$. Pericarpo amadurecido, após ter perdido água. Notar canais secretores circundados por fina camada de células (setas) $($ barra $=500 \mu \mathrm{m})$. CO = cotilédone, $\mathrm{CS}=$ canal secretor, $\mathrm{EN}=$ endocarpo, $\mathrm{EX}=$ exocarpo, $\mathrm{MS}=$ mesocarpo, $\mathrm{PQ}=$ paquicalaza .

cubóides, ligeiramente alongadas radialmente; as camadasinterepidérmicassãoconstituídas portrêsa sete camadas de células parenquimáticas de formatos e tamanhos variados, seguidas por uma rede de feixes vasculares anficrivais e por um grupo de 
células parenquimáticas com parede espessada e conteúdo tanífero, que constitui a hipóstase (sensu lato) (figura 17).
O envoltório da semente madura é uma película muito fina, adnata ao pericarpo, constituída por restos da testa, rafe, calaza e hipóstase (figura 16). $\mathrm{Na}$
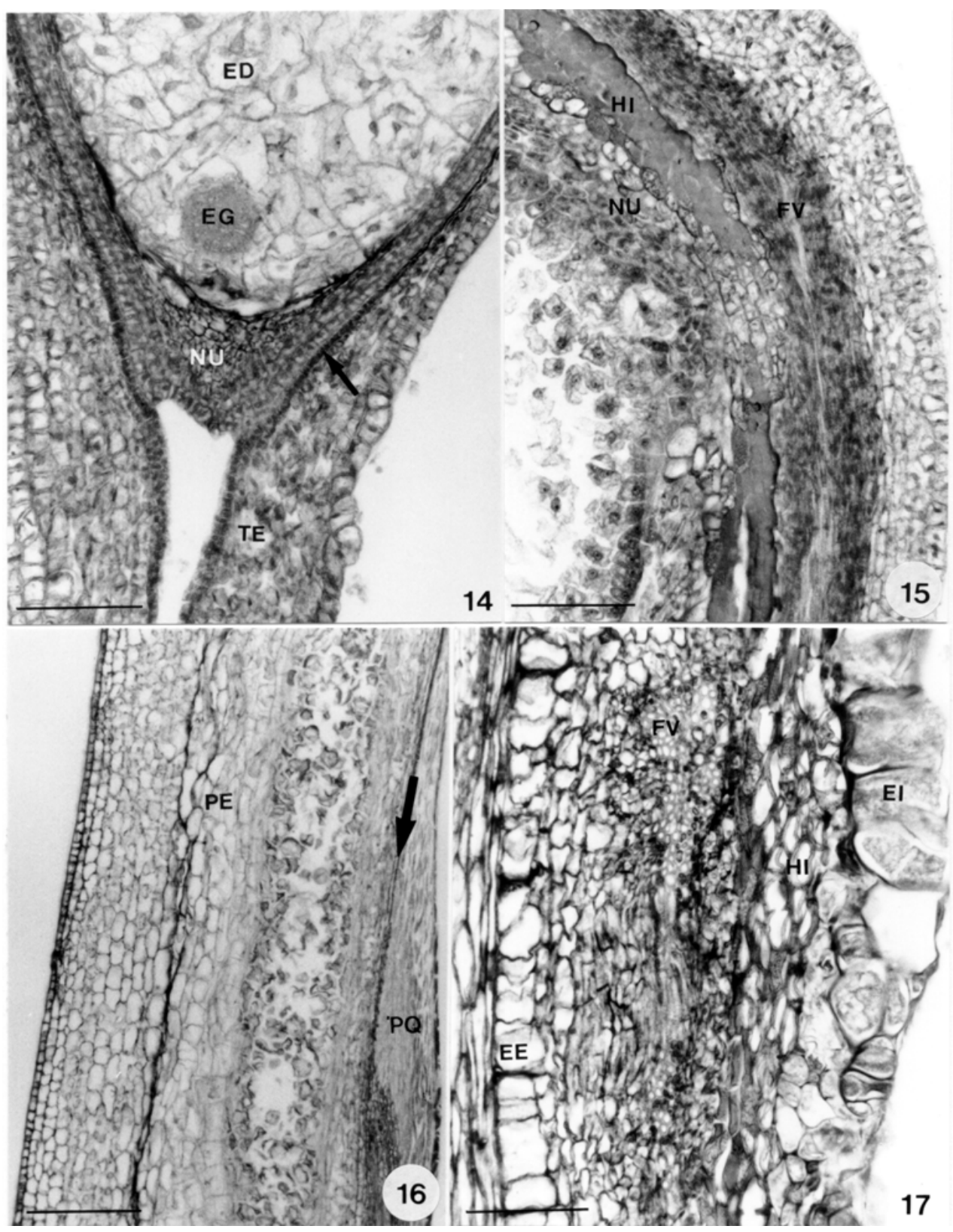

Figuras 14-17. 14. Secção longitudinal da semente imatura, na região da micrópila. A seta indica epiderme interna da testa $($ barra $=250 \mu \mathrm{m}) .15$. Secção longitudinal da semente imatura na região da calaza (barra $=125 \mu \mathrm{m}) .16$. Secção longitudinal do pericarpo aderido à semente. A seta indica o limite entre o pericarpo e a semente (barra $=150 \mu \mathrm{m}) .17$. Secção transversal da semente na região calazal $($ barra $=50 \mu \mathrm{m}) . \mathrm{ED}=$ endosperma, $\mathrm{EE}=$ epiderme externa, $\mathrm{EG}=$ embrião globular, $\mathrm{EI}=$ epiderme interna, $\mathrm{FV}=$ feixe vascular, $\mathrm{HI}=$ hipóstase, $\mathrm{NU}=$ nucelo, $\mathrm{PE}=$ pericarpo, $\mathrm{PQ}=$ paquicalaza, $\mathrm{TE}=$ testa . 
anti-rafe, o envoltório fica constituído apenas pela epiderme interna da testa, indicando uma condição endotestal.

As células do funículo, a medida que a semente se desenvolve, colapsam e restos ficam aderidos ao envoltório da semente, sugerindo a presença de um arilo funicular vestigial (figura 2).

\section{Discussão}

A família Anacardiaceae distingue-se de famílias aparentadas pela combinação de características tais como: disco intra-estaminal, presença de canais resiníferos, ovário geralmente unilocular e frutos drupáceos (Wannan \& Quinn 1990).

Segundo Roth (1977), a classificação dos frutos ainda é um problema não solucionado. Muitos caracteres diferentes tais como estrutura do ovário, número de carpelos e sementes, morfologia e anatomia do fruto, dispersão dos frutos e sementes, deiscência ou indeiscência e consistência do pericarpo são utilizados na caracterização dos diferentes tipos de frutos. Todavia, o que ocorre freqüentemente é que alguns autores introduzem vários subtipos na classificação, gerando confusão.

Os frutos também têm sido classificados, por muitos autores, de acordo com sua origem, com a consistência do pericarpo e o modo de deiscência (McLean \& Ivimey-Cook 1968, Radford et al. 1974, Weberling \& Schwantes 1986, Bell \& Bryan 1991, Raven et al. 1992). Santin (1989), considerando o fruto de Astronium totalmente desenvolvido mas não amadurecido, utilizou-se desses critérios e classificou-o como baga. Já Barroso et al. (1999), usando os mesmos critérios, classificou-os como frutos simples, secos indeiscentes, nucóides-núcula.

O exo e o mesocarpo podem variar em espessura entre as Anacardiaceae. $\mathrm{O}$ exocarpo pode ser formado apenas pela epiderme ou pela epiderme mais a hipoderme e o mesocarpo é formado, principalmente, por células parenquimáticas entremeadas por canais secretores associados a feixes vasculares e comumente circundados por grupos de esclereídes ou células cristalíferas (Wannan \& Quinn 1990). Em Astronium graveolens, o exocarpo é unisseriado e suberificado e o mesocarpo é totalmente parenquimático no fruto desenvolvido, mas não maduro. No fruto maduro, as células parenquimáticas perdem água e colapsam, dando aspecto enrugado ao fruto, e os canais secretores, bem desenvolvidos e cheios de secreção, caracterizam o mesocarpo como resinoso.

Na descrição do pericarpo, seguindo-se a separação por tribos feita por Engler (1892) em Spondiadeae, Rhoeae, Dobineeae, Semecarpeae e Anacardieae, Wannan \& Quinn (1990) chegaram a conclusão que existem dois tipos básicos estruturais de endocarpo. O primeiro tipo, composto de uma massa de esclerênquima fortemente lignificada e irregulamente orientada, designado tipo-Spondias. O segundo, com arranjo em camadas e, freqüentemente, incluindo esclereídes em paliçada, designado tipo-Anacardium.

A tribo Rhoeae, a qual pertence Astronium, foi dividida em três grupos: $\mathrm{A}, \mathrm{B}$ e $\mathrm{C}$, sendo que os grupos A e B apresentam endocarpo do tipoAnacardium e o grupo C, do tipo-Spondias. Dentro do grupo A, estão incluídos os gêneros Astronium, Cotinus, Euroschinus, Laurophyllus, Loxostylis, Ozoroa, Rhodosphaera, Rhus, Schinopsis e Schinus (Wannan \& Quinn 1990), além de Lithraea e Myracrodruon (Carmello-Guerreiro 1996), em que o endocarpo é composto de quatro camadas celulares, sendo as três mais internas formadas por esclereídes em paliçada, enquanto que a camada mais externa é formada por células cristalíferas, pequenas e, algumas vezes, não lignificadas.

O grupo B é composto por três gêneros, Mauria, Parishia e Pistacia, em que o endocarpo parece ser derivado do grupo A. Em Mauria e Parishia, o endocarpo é composto de duas a três camadas celulares parenquimáticas, condição esta resultante da ausência de uma ou duas camadas em paliçada, uma vez que a camada de cristais está sempre presente. Em Pistacia, o endocarpo é lignificado com mais de quatro camadas, mas não tem um arranjo regular (Wannan \& Quinn 1990).

O grupo C tem endocarpo com esclereídes orientadas irregularmente; não há, no entanto, arranjo nítido em quatro camadas ou esclereídes em paliçada. A irregularidade na orientação das esclereídes sugere que estes gêneros são aparentados das Spondiadeae (Wannan \& Quinn 1990).

Os frutos de Astronium apresentam endocarpo com algumas características semelhantes às do endocarpo do tipo-Anacardium-grupo $\mathrm{B}$, no qual o 
endocarpo é uma epiderme bisseriada não esclerificada e sem camada cristalífera. Este resultado é discordante do apresentado por Wannan \& Quinn (1990), que incluiram o gênero Astronium no grupo A, juntamente com Myracrodruon. Acredita-se que esta discordância deva-se ao fato de que Wannan \& Quinn (1990) analisaram Astronium urundeuva, que só após a revalidação do gênero Myracrodruon por Santin \& Leitão-Filho (1991), passou a ser denominado de Myracrodruon urundeuva.

A ocorrência de endocarpo originado de epiderme bi ou multisseriada não está limitada apenas a tribo Rhoeae, sendo também encontrado em Swintonia da tribo Anacardieae, que consiste de duas ou três camadas celulares, não lignificadas, diferentes do mesocarpo por sua forma colunar, arranjo regular e ausência de camada cristalífera (Wannan \& Quinn 1990).

Conclui-se que o endocarpo de Astronium graveolens, na realidade, é uma mistura das características do tipo-Anacardium da tribo Rhoeaegrupo B com de Swintonia da tribo Anacardieae, apresentando endocarpo constituído por epiderme bisseriada não esclerificada, sem camada cristalífera, sendo a camada mais interna ligeiramente alongada radialmente. Além da estrutura do endocarpo, o tipo de fruto de Astronium, uma pseudosâmara, também é coincidente com o de Swintonia da tribo Anacardieae.

As informações apresentadas reforçam as conclusões de Wannan \& Quinn (1990) de que os limites entre as tribos da família Anacardiaceae e famílias aparentadas são ainda artificiais, sendo esta conclusão corroborada pela ocorrência de um mesmo tipo de endocarpo em tribos diferentes e em famílias aparentadas como Julianiaceae e Blepharocaryaceae.

No pericarpo de A. graveolens, o exo e o mesocarpo são bem delimitados e o endocarpo é representado por uma epiderme bisseriada, sem qualquer lignificação, que no fruto maduro está colapsada e adnata à semente. Desta forma, estes frutos não devem ser tipificados como drupa, discordando de Barkley (1942, 1957), Bernardi (1959), Soukup (1969) e Rizzini (1978).

Barroso et al. (1984), Santin (1989) e Santin \& Leitão-Filho (1991) tipificaram os frutos de $A$. graveolens, quando maduros mas, ainda, não separa- dos da planta-mãe, como baga e, Barroso et al. (1999) tipificou-os como núcula quando separados da planta-mãe. Entretanto, levando-se em conta as características morfológicas da unidade de dispersão, as características anatômicas do pericarpo e o conceito de fruto adotado por Spjut (1994), assumese, neste trabalho, que os frutos de Astronium são melhor tipificados como pseudo-sâmara, na qual o antocarpo é circundado por asas distais, com duas ou mais vezes o comprimento do pericarpo, sendo as asas formadas pelo cálice acrescente.

Os óvulos de Anacardiaceae são descritos como anátropos com funículo de inserção basal ou apical. Em adição a essas duas situações, existe uma intermediária que Copeland (1959) referiu como um funículo lateral. A inserção dos óvulos é constante em Dobineeaea (basal) e em Spondieae (apical) mas, varia em Anacardieae, Semecarpeae e Rhoeae. Nas Anacardiaceae, os óvulos de inserção apical são mais comuns, enquanto que os de inserção basal são considerados uma condição derivada (Wannan \& Quinn 1991, Von Teichman 1993). Os óvulos de Astronium graveolens têm inserção apical-lateral e os de Myracrodruon urundeuva têm inserção basallateral (Carmello-Guerreiro 1996), portanto, mais uma característica de relevância taxonômica que difere entre os dois gêneros.

$\mathrm{O}$ crescimento da placenta em direção à micrópila foi considerado, neste trabalho, como um obturador placentário, porém, sua função deve ser investigada uma vez que a entrada e o curso do tubo polínico é variável em Anacardiaceae (Johri et al. 1992), havendo vários relatos da ocorrência de calazogamia.

A análise anatômica revelou que a testa está fortemente adnata ao pericarpo, apresentando as células da epiderme interna pequenas e de conteúdo denso, indicando uma condição endotestal. $\mathrm{O}$ envoltório, na semente madura, é formado por duas regiões distintas, uma tegumentar, constituida por restos da testa, e outra calazal ou parcialmente paquicalazal, constituida pelo funículo, região rafe-calazal e hipóstase. A calaza extensa e a hipóstase (sensu lato) tanífera se manifestam externamente como uma mancha marrom-escura, isto é, a parte calazal do envoltório ou paquicalaza parcial.

Segundo Von Teichman (1991a), uma pequena paquicalaza parcial e a epiderme interna do tégmen 
lignificada caracterizam as sementes dos membros da tribo Rhoeae. Essas observações concordam com Corner (1976), que relatou serem os envoltórios das sementes das Anacardiaceae pouco ou não especializados, ou apenas endotégmicos ou com traços de uma condição exotestal. Nas observações apresentadas neste trabalho, pode-se concordar em parte com os autores acima citados, uma vez que o tegumento da semente de Astronium é, também, pouco diferenciado, porém, com traços de uma condição endotestal. A ocorrência de sementes paquicalazais com envoltórios indiferenciados parece estar intimamente associada a habitats tropicais (Von Teichman 1991a).

A presença de sementes com envoltório membranáceo e liso no qual pode-se dintinguir duas regiões de coloração diferentes, uma amarelo-clara (tegumentar) e outra marrom-escura (paquicalazal), é muito comum nas Anacardiaceae e já foi verificada em outras espécies por Copeland \& Doyel (1940), Copeland (1955, 1959, 1961), Corner (1976), Von Teichman et al. (1988), Von Teichman \& Van Wyk (1988, 1991), Von Teichman (1988a, b, 1990, 1991a, b, 1992, 1993, 1994) e Carmello-Guerreiro (1996), parecendo ser uma característica da família variando apenas o grau de desenvolvimento da paquicalaza.

Além das diferenças no tipo de fruto, estrutura do pericarpo e placentação entre Astronium e Myracrodruon, o tipo de embrião também foi uma característica importante para a separação dos dois gêneros. Astronium apresenta embrião do tipo "investing", com cotilédones carnosos, maciços, de lobos bem demarcados e o eixo-hipocótilo-radícula curto, enquanto que Myracrodruon apresenta embrião dobrado, com cotilédones carnosos, não maciços, e eixo hipocótilo-radícula longo (Santin 1989, Santin \& Leitão-Filho 1991, Carmello-Guerreiro 1996).

Agradecimentos - Agradecemos à CAPES e FAPESP pelas bolsas de doutorado concedidas a S.M. CarmelloGuerreiro.

\section{Referências bibliográficas}

BARKLEY, F.A. 1942. A key to the genera of the Anacardiaceae. American Midland Naturalist 28:465-74.
BARKLEY, F.A. 1957. Generic key to the Sumac family. Lloydia 20:255-65.

BARKLEY, F.A. 1968. Anacardiaceae: Rhoideae: Astronium. Phytologia 16:107-52.

BARROSO, G.M., PEIXOTO, A.L., COSTA, C.G., ICHASO, C.L.F., GUIMARÃES, E.F., LIMA, H.C. 1984. Sistemática das Angiospermas do Brasil. Imprensa Universitária, Viçosa, v.2.

BARROSO, G.M., MORIM, M.P., PEIXOTO, A.L., ICHASO, C.L.F. 1999. Frutos e sementes: morfologia aplicada à sistemática de dicotiledôneas. Editora da Universidade Federal de Viçosa, Viçosa.

BELL, A. \& BRYAN, A. 1991. An illustrated guide to flowering plant morphology. Oxford University Press, Oxford.

BERNARDI, L.A. 1959. El genero Astronium. Boletin de la Sociedad Venezolana de Ciências Naturales 20:348-59.

CARMELLO-GUERREIRO, S.M. 1996. Morfologia, anatomia e desenvolvimento dos frutos, sementes e plântulas de Schinus terebinthifolius Raddi, Lithraea molleoides (Vell.) Engl., Myracrodruon urundeuva Fr. Allem. e Astronium graveolens Jacq. (Anacardiaceae). Tese de doutorado, Universidade Estadual Paulista, Rio Claro.

COPELAND, H.F. 1955. The reproductive structures of Pistacia chinensis (Anacardiaceae). Phytomorphology 5:440-449.

COPELAND, H.F. 1959. The reproductive structures of Schinus molle (Anacardiaceae). Madrõno 15:14-24.

COPELAND, H.F. 1961. Observations on the reproductive structure of Anacardium occidentale. Phytomorphology 11:315-325.

COPELAND, H.F. \& DOYEL, B.E. 1940. Some features of the structure of Toxicodendron diversiloba. American Journal of Botany 27:932-939.

CORNER, E.J.H. 1976. The seeds of Dicotyledons. Cambridge University Press, Cambridge.

ENGLER, A. 1892. Anacardiaceae. In Die Naturlichen Planzenfamilien (A. Engler \& K. Prantl, eds.). Englemann, Leipzig, v.3, p.138-178.

GERRITS, P.O. 1991. The application of glycol methacrylate in histotechnology: some fundamental principles. Departament of Anatomy and Embryology State University Groningen, Netherlands.

JOHANSEN, D.A. 1940. Plant microtechnique. McGrawHill Book, New York.

JOHRI, B.M., AMBEGAOKAR, K.B. \& SRIVASTAVA, P.S. 1992. Comparative embryology of Angiosperms. v.1. Springer-Verlag, New York.

McLEAN, R.C. \& IVIMEY-COOK, W.R. 1968. Textbook of theoretical botany. Longman, London. 
O'BRIEN, T.P., FEDER, N. \& McCULLY, M.E. 1964. Polychromatic staining of plant cell walls by toluidine blue O. Protoplasma 59:368-373.

RADFORD, A.E., DICKINSON, W.C., MASSEY, J.R. \& BELL, C.R. 1974. Vascular plant systematics. Harper \& Row, New York.

RAVEN, P.H., EVERT, R.F. \& EICHHORN, S.E. 1992. Biology of plants. Worth Publishers, NewYork.

RIZZINI, C.T. 1978. Árvores e madeiras úteis do Brasil: manual de dendrologia brasileira. Edgard Blücher, São Paulo.

ROTH, I. 1977. Fruits of Angiosperms: encyclopedia of plant anatomy. Gebrüder Borntraeger, Berlin.

SANTIN, D.A. 1989. Revisão taxonômica do gênero Astronium Jacq. e revalidação do gênero Myracrodruon Fr. Allem. (Anacardiaceae). Dissertação de mestrado, Universidade Estadual de Campinas, Campinas.

SANTIN, D.A. 1991. Astronium nelson-rosae - nova espécie de Anacardiaceae. Revista Brasileira de Botânica 14:103-106.

SANTIN, D.A. \& LEITÃO-FILHO, H.F. 1991. Restabelecimento e revisão taxonômica do gênero Myracrodruon Freire-Allemão (Anacardiaceae). Revista Brasileira de Botânica 14:133-145.

SOUKUP, J. 1969. The Trigoniaceae, Vochysiaceae, Coriariaceae and Anacardiaceae of Peru, their genera and list of species. Biota 7:303-404.

SPJUT, R.W. 1994. A systematic treatment of fruit types. Memoirs of the New York Botanical Garden 70:1-82.

VON TEICHMAN, I. 1988a. Development and structure of the seed-coat of Lannea discolor (Sonder) Engl. (Anacardiaceae). Botanical Journal of the Linnean Society 96:105-117.

VON TEICHMAN, I. 1988b. Notes on the ontogeny and structure of the seed-coat of Sclerocarya birrea (Richard) Hochst subsp. caffra (Sonder) Kokwaro (Anacardiaceae). Botanical Journal of the Linnean Society 98:153-158.

VON TEICHMAN, I. 1990. Pericarp and seed-coat structure in Tapirira guianensis (Spondiadeae: Anacardiaceae). South African Journal of Botany 56:435-4399.
VON TEICHMAN, I. 1991a. The pachychalazal seed of Protorhus longifolia (Bernh.) Engl. (Anacardiaceae) and its taxonomic significance. Botanical Bulletin of Academia Sinica (Taipei) 32:145-152.

VON TEICHMAN, I. 1991b. Ontogeny of seed-coat of Rhus lancea L. fil., and pachychalazy in the Anacardiaceae. Botanical Journal of the Linnean Society 107:35-47.

VON TEICHMAN, I. 1992. Notes on the ovule and partially pachychalazal seed of Operculicarya decaryi H. Perrier (Anacardiaceae) from Madagascar. Botanical Bulletin of Academia Sinica (Taipei) 33:289293.

VON TEICHMAN, I. 1993. Development and structure of the seed of Ozoroa paniculosa (Anacardiaceae) and taxonomic notes. Botanical Journal of the Linnean Society 111:463-470.

VON TEICHMAN, I. 1994. Generic position of Protorhus namaquensis Sprague (Anacardiaceae): evidence from seed structure. Botanical Bulletin of Academia Sinica (Taipei) 35:53-60.

VON TEICHMAN, I. \& VAN WYK, A.E. 1988. The ontogeny and structure of the pericarp and seed-coat of Harpephylum caffrum Bernh. ex. Kraus (Anacardiaceae). Botanical Journal of the Linnean Society 98:159-176.

VON TEICHMAN, I. \& VAN WYK, A.E. 1991. Taxonomic position of Rhus problematodes (Anacardiaceae): evidence from fruit and seed structure. South African Journal of Botany 57:29-33.

VON TEICHMAN, I., ROBBERTSE, P.J. \& SCHOONRAAD, E. 1988. The structure of the seed of Mangifera indica L. and notes on seed characters of the tribe Mangifereae (Anacardiaceae). South African Journal of Botany 54:472-76.

WANNAN, B.S. \& QUINN, C.J. 1990. Pericarp structure and generic affinities in the Anacardiaceae. Botanical Journal of the Linnean Society 103:225-52.

WANNAN, B.S. \& QUINN, C.J. 1991. Floral structure and evolution in the Anacardiaceae. Botanical Journal of the Linnean Society 107:349-85.

WEBERLING, F. \& SCHWANTES, H.O. 1986. Taxionomia vegetal. EPU, São Paulo. 